\title{
Operation Efficiency Evaluation of the China-Europe Freight Train Based on Grey Cross-Efficiency DEA
}

\author{
Jun Zhang, ${ }^{1,2}$ Jianpeng Chang, ${ }^{1,2}$ Ping Lin, ${ }^{2}$ Minzi Song $\mathbb{D},{ }^{3}$ and Yanqiu Gong ${ }^{4}$ \\ ${ }^{1}$ Enterprise Management Research Center, Chongqing Technology and Business University, Chongqing 400067, China \\ ${ }^{2}$ School of Management Science and Engineering, Chongqing Technology and Business University, Chongqing 400067, China \\ ${ }^{3}$ School of Foreign Language, Chongqing Technology and Business University, Chongqing 400067, China \\ ${ }^{4}$ College of Business Administration, Chongqing Technology and Business University, Chongqing 400067, China
}

Correspondence should be addressed to Minzi Song; songminzi@email.ctbu.edu.cn

Received 9 July 2020; Revised 28 August 2020; Accepted 16 September 2020; Published 31 October 2020

Academic Editor: Tingsong Wang

Copyright $\odot 2020$ Jun Zhang et al. This is an open access article distributed under the Creative Commons Attribution License, which permits unrestricted use, distribution, and reproduction in any medium, provided the original work is properly cited.

\begin{abstract}
The China-Europe Freight Train (CEFT) serves as an important carrier and platform for international economic cooperation and international trade circulation between China and Europe. Since it worked, its actual operation and development have been affected by many factors, but the level of its actual operating efficiency and the main affecting factors of CEFT have been difficult to find, which has severely limited its sustainable development. Therefore, this paper scientifically selected the operation efficiency evaluation indicator system of CEFT and combined grey system theory, cross-efficiency method, and DEA to construct a new DEA evaluation model based on grey cross-efficiency, which can not only overcome the problem of ignoring the relative importance ratings of the evaluation indicator in the general DEA evaluation model and the traditional crossefficiency DEA evaluation model but also more accurately evaluate the actual operation efficiency of CEFT. At the same time, based on the actual operating data of CEFT from 2011 to 2018 and the above new evaluation models, the CEFT's operation efficiency was evaluated and tested by examples, showing that on the one hand, the grey cross-efficiency DEA evaluation model can more accurately evaluate the actual operation efficiency of CEFT than other traditional evaluation models; on the other hand, it is found that the "overseas cities," "operating lines," and "entry-exit nodes" are currently the main factors that limit the actual operation efficiency of CEFT and indicating improvement direction for the future efficient and sustainable development of CEFT.
\end{abstract}

\section{Introduction}

On March 19, 2011, the "Chongqing-Sinkiang-Europe International Railway" container freight train from Chongqing, China, to Duisburg, Germany, was launched, marking the official opening of the new railway freight model between China and Europe, the China-Europe Freight Train (CEFT). The CEFT connected the two strategic spaces of the Silk Road Economic Belt and the Yangtze River Economic Belt, and it served as an important carrier and platform for the country to promote the "Belt and Road" initiative. Moreover, it also broke the foreign trade pattern that focused on the eastern coastal cities after China's reform and opening up, making the Midwest region a bridgehead that opens to the west. Since it began to work, the CEFT has not only achieved major breakthroughs in terms of scale, coverage, and freight category but also formed a relatively clear operation model and a relatively stable operation pattern. In 2019, the CEFT ran 8,225 trains and delivered 725,000 TEUs, with a comprehensive reload rate of $94 \%$, and has embarked on a normalized and large-scale development path. However, after several years of disorderly development, a series of problems on the operation of the CEFT have been revealed, such as high costs, disorderly competition, insufficient supply and demand connection, and low customs clearance efficiency. Therefore, the purpose of this paper is to conduct a comprehensive scientific evaluation of the operation efficiency of the CEFT, explore the essential causes, and propose targeted solutions. 
Until now, no scholars have studied the operation efficiency of the CEFT, but some scholars have discussed the operation efficiency of railways. Existing studies have either focused on the operation efficiency of railway passenger transport, or on rail freight transport, or on the comprehensive efficiency of the railway system. Moreover, existing studies mostly use DEA or its improved forms to measure the operation efficiency of the railway system, mainly because specific production function forms are not needed to be set in advance. This paper used the DEA method to evaluate the annual operation efficiency of the CEFT since its inception and explore its current operation status and its shortcomings. Even though the cross-efficiency DEA model can achieve the ranking of alternatives, it cannot distinguish the relative size of the weights of inputs and outputs. Therefore, to solve this problem, this paper introduced the grey system theory, proposed a cross-efficiency DEA model based on grey correlation, and fixed the proportional relationship between input or output index weights, carrying out the efficiency evaluation of the CEFT.

\section{Research Status}

At present, there have been many researches on the efficiency of railway operations, and the topics covered are broad. They can be further divided into two categories according to the research theme: one is to explore the impact of railway operation efficiency on the economic and social environment, such as the impact of railway transport on green innovation efficiency [1] and the impact on energy and environmental protection efficiency $[2,3]$, while the other is to explore how to improve railway operation efficiency, namely, attempt to identify the problems in the development of railway operations by evaluating the efficiency of railway operations, and then put forward targeted recommendations $[4,5]$, and in this paper, the second category has been drawn attention. Initially, relevant studies treated railway passenger transport and freight transport equally and explored the comprehensive railway operation efficiency $[6,7]$. However, due to the significant differences between the railway passenger transport and freight transport in the process of operation, Yu and Lin $[8,9]$ and $\mathrm{Li}[10]$ pointed out that the efficiency of the railway passenger transport and railway freight transport should be studied within a unified framework, respectively. Therefore, the research on how to improve the efficiency of railway operation can be further divided into three types, one is the research on the operation efficiency of the railway passenger transport, another is the research on the operation efficiency of the railway freight transport, and the last is the research on the comprehensive operation efficiency of the railway passenger and freight transport. The network DEA method was employed to measure the railway passenger transport operation efficiency, freight operation efficiency, service efficiency, and technical efficiency of the 20 railway systems in 2002 and further compared the network DEA to the traditional DEA, pointing out that the network DEA owned greater advantages than the traditional DEA in the railway and could provide more information about improvements in railway efficiency [9]. Besides, Sameni et al. and Preston [11] used DEA to measure the operational efficiency of the British railway passenger transport and explored the utilization of railway capacity. Friebel et al. [12] used PMF (Production Frontier Model) to study the reform efficiency of the EU railway passenger transport system. In another paper, Kutlar et al. [13] used CCR (the abbreviation of its developers' initials, i.e., Charnes, Cooper, and Rhodes [14]) and BCC (the abbreviation of its developers' initials, i.e. Banker, Charnes, and Cooper [15]), respectively, to evaluate the technical efficiency and resource allocation efficiency of 31 railway operation companies in the world from 2000 to 2009 . The two methods obtained results with obvious differences, mainly because the BBC considered the factor of scale returns compared to CCR.

Many methods can be applied to study the efficiency of railway operation and can be divided into the following four categories according to whether boundaries and parameters have been set [10]: first is the parametersnonboundary method represented by Tobit and OLS, which is applicable to the factors analysis affecting efficiency; the second is the nonparameter and nonboundary method represented by the total productivity index, which has strict restrictions on the price index of the input and output; the third is the parameter-boundary method, which can be further divided into random boundary method and fixed boundary parameter method; the former is more sensitive to the assumption of the distribution method of random variables, while the latter choosing different production functions may lead to different results; the fourth is the nonparametricboundary method represented by data envelopment analysis (DEA). DEA is a tool for evaluating the relative efficiency of homogeneous decision-making units with multiple inputs and outputs. Compared with other efficiency evaluation tools, it does not require the setting of specific production function forms in advance, nor does it require to determine the relevant input and output weights, only input and output data are required, and no other processing is required for the data. Because of its outstanding advantages, DEA has received extensive attention in the academic and practical fields since its introduction. In theory, DEA was first proposed by Charnes et al. [14] in 1978 and the original DEA model was called the CCR model, which aimed to quantify the relative efficiency of all decision-making units by constructing an effective production frontier. Then, in 1984, Banker et al. [15] proposed the BCC model based on CCR, which considered variable scale efficiency. Since then, DEA models with different characteristics and functions, such as the cross-efficiency model [16], confidence interval model [17], cone scale model [18], and super-efficiency model [19], have been proposed. In terms of application, DEA and its improved forms have been 
widely used in efficiency research in various fields, including transport system [20], education system [21], construction field [22], tourism industry [23], environmental protection field [24], and hospital system [25].

\section{Selection of Evaluation Indicators for Operation Efficiency of CEFT}

This section aims to build a scientific, objective, and reasonable operation efficiency evaluation indicator system for CEFT.

The construction of the indicator system needs to strictly follow the principles of representativeness, completeness, specificity, scientificity, accessibility, and independence. We divided the construction process of the indicator system into two phases, namely, the preliminary screening phase and the key screening phase.

3.1. Phase 1: the Preliminary Indicator Screening. This paper used the analytical method to carry out the first screening of indicators. First of all, the theoretical knowledge related to the evaluation of operation efficiency has been fully familiarized with, and concurrently the background knowledge, development status, construction results, etc., of the operation of CERT have been carefully studied. On the basis of a certain understanding of the theory and actual situation, by referring to relevant literature and documents, the development connotation of CERT has been analyzed and determined; finally, the appeals of interest subjects have been analyzed from the perspectives of three different interest subjects. The freight owners, freight forwarding, and operating companies of CERT have different evaluation on operation efficiency. For example, from the perspective of the freight owners, the main considerations are speed and time efficiency and transport costs, while for the freight forwarding, the primary considerations are the scale of transport and freight security, and the economic and trade contribution brought by the operation of the train is what the operating companies focus on. Through the above analysis, the operation efficiency of CERT can be divided into six levels: scale range, speed efficiency, transport efficiency, transport cost, economic and trade contribution, and freight traffic safety.

(i) The range of scale is an important indicator for evaluating the development volume and scale efficiency of CEFT and is also the basis for judging the different stages of development of CEFT. Within a certain period, increasing the scale of CEFT is the key way to reduce the operation costs.

(ii) The speed efficiency is a significant manifestation of the high-quality operation of CEFT. Increasing the average delivery speed and ensuring the logistics efficiency of the whole process are also an effective way to improve the operation quality of CEFT.

(iii) The transport efficiency indicator describes the level of transport capacity and nodes smoothness of the CEFT, the level of transport, and organization such as the scheduling, negotiation, and implementation, and the overall efficiency of the use of transport resources such as fixed facilities and mobile equipment.

(iv) The transport cost is the transport expenditure shared by CEFT in order to complete the transport workload, and it is an important basis for CEFT to set the price of the freight transport and the main factor for disorderly competition of freight sources.

(v) The economic and trade contribution reflects the relations between the logistics development of CEFT and China-EU economic and trade exchanges, showing the contribution of CEFT to the development of Sino-European trade.

(vi) The freight traffic safety statistics, such as the frequency of operational safety accidents, freight damage and freight theft, and international insurance business volume of CEFT are important indicators that can reflect the CEFT's overall freight safety guarantee and risk prevention and control capabilities.

After the evaluation indicator layer was determined, the preliminary indicator layer that met the CEFT efficiency evaluation was set according to the construction principles of the CEFT efficiency evaluation indicator. And then, after considering relevant experts' advisory opinions, the representative subindicators have been identified, forming a preliminary evaluation indicator system with 6 indicator layers and 33 subindicator layers, which are presented in Table 1.

3.2. Phase 2: the Key Indicator Screening. In the preliminary indicator system, there exist overlaps between subindicators, easily leading to distorted evaluation results. Therefore, it was necessary to further screen the 33 subindicators.

In this phase, we adopt the method of expert survey to screen the subindicators. Firstly, we selected 60 experts to conduct a questionnaire. The selecting process is presented as follows.

(i) Step 1: defining the aims of selecting experts. In this case, the aim is to assess the importance of subindicators which are used for evaluating the operation efficiency of CEFT.

(ii) Step 2: specifying the criteria of selection experts. In this case, the criteria include experience, knowledge, willingness, time, and independence.

(iii) Step 3: finding expert sources. In this case, we select experts from railway administrations, logistic enterprises, governments, research institutions, and universities.

(iv) Step 4: selecting alternatives. In this case, we identify 60 alternative experts based on the criteria specified in Step 2.

In order to ensure the professionalism, experts with a higher degree of knowledge on logistics and railway operation, government leaders with at least 10 years of related 
TABle 1: Preliminary indicator system for operation efficiency evaluation of CEFT.

\begin{tabular}{|c|c|c|}
\hline Indicator layer & Subindicator layer & Indicator description \\
\hline \multirow{11}{*}{ Scale range } & Annual operation trains & The number of annual operation trains \\
\hline & Annual outbound trains & The number of outbound trains in one year \\
\hline & Annual inbound trains & The number of inbound trains in one year \\
\hline & Annual containers & The number of all containers actually carried by the CEFT in one year \\
\hline & $\begin{array}{l}\text { Annual outbound } \\
\text { containers }\end{array}$ & The total number of containers actually carried in the outbound CEFT in one year \\
\hline & Annual inbound containers & The total number of containers actually carried in the inbound CEFT in one year \\
\hline & Train return ratio & $\begin{array}{c}\text { The ratio of the returned trips to the total trips, reflecting the balance of the two-way trips } \\
\text { between China and Europe }\end{array}$ \\
\hline & $\begin{array}{l}\text { Ratio of returned } \\
\text { containers }\end{array}$ & $\begin{array}{l}\text { The ratio of the returned containers to the total number of freight containers transported } \\
\text { by the train, reflecting the organization of the returned freight of CEFT }\end{array}$ \\
\hline & Domestic cities & The number of cities with entry-exit nodes of CEFT in China \\
\hline & Overseas cities & The number of overseas cities with entry-exit nodes of CEFT \\
\hline & Container conversion & $\begin{array}{l}\text { The actual number of containers carried by CEFT is converted into the number of trains in } \\
\text { accordance with the standard of carrying } 41 \text { containers per train. }\end{array}$ \\
\hline Speed efficiency & $\begin{array}{l}\text { Average time } \\
\text { Average speed }\end{array}$ & $\begin{array}{c}\text { The "station-to-station" transport time of CEFT, including transit time plus node stay time } \\
\text { The ratio of CEFT transport mileage to transport time }\end{array}$ \\
\hline \multirow{7}{*}{$\begin{array}{l}\text { Transport } \\
\text { efficiency }\end{array}$} & Operating lines & $\begin{array}{l}\text { The number of CEFT running lines among China, Europe, and countries along the belt and } \\
\text { road, including trunk lines and branch lines }\end{array}$ \\
\hline & Entry-exit nodes & The number of entry-exit nodes of CEFT in China \\
\hline & Capacity utilization & The ratio of actual train operation to the maximum train operation \\
\hline & Average static load rate & $\begin{array}{l}\text { The average of the static load of the loaded containers, reflecting the degree of utilization of } \\
\text { the freight transport capacity provided by the CEFT to the freight railways }\end{array}$ \\
\hline & Full-capacity rate & The ratio of the loaded containers with full capacity to the number of all loaded containers \\
\hline & Fulfilled rate & The ratio of the actual number of CEFT to the number of scheduled CEFT \\
\hline & Loaded container rate & The ratio of the number of loaded containers to the total number of containers \\
\hline \multirow{2}{*}{ Operation cost } & $\begin{array}{l}\text { Average freight charges of } \\
\text { operation }\end{array}$ & $\begin{array}{c}\text { The cost of transporting } 1 \text { container for } 1 \mathrm{~km} \text {. The average freight charges of the } \\
\text { train }=(\text { domestic freight }+ \text { foreign freight }) / \text { total mileage }\end{array}$ \\
\hline & Government subsidy & $\begin{array}{c}\text { Financial support by the local government, referring to the benchmark of freight of each } \\
\text { train }\end{array}$ \\
\hline \multirow{7}{*}{$\begin{array}{l}\text { Economic and } \\
\text { trade }\end{array}$} & Total value of annual freight & $\begin{array}{c}\text { The value of importing-exporting freights on CEFT, reflecting the status and role of CEFT } \\
\text { in China-EU economic and trade cooperation }\end{array}$ \\
\hline & $\begin{array}{l}\text { Total value of the outbound } \\
\text { freight }\end{array}$ & The value of exported freights on CEFT in one year \\
\hline & $\begin{array}{l}\text { Total value of the inbound } \\
\text { freight }\end{array}$ & The value of imported freights on CEFT in one year \\
\hline & Unit TEU value & $\begin{array}{l}\text { The average value per TEU of freight transported by CEFT, indicating the segmentation } \\
\text { and target positioning of the CEFT logistics market }\end{array}$ \\
\hline & Outbound unit TEU value & $\begin{array}{l}\text { The average value per TEU of freights transported by outbound CEFT, indicating the } \\
\text { segmentation and target positioning of the CEFT logistics market }\end{array}$ \\
\hline & Inbound unit TEU value & $\begin{array}{l}\text { The average value per TEU of freights transported by inbound CEFT, indicting the } \\
\text { segmentation and target positioning of the CEFT logistics market }\end{array}$ \\
\hline & $\begin{array}{l}\text { Ratio of key categories } \\
\text { China-EU total trade }\end{array}$ & $\begin{array}{c}\text { The ratio of the number of TEU of the top } 5 \text { categories to the total number of TEU } \\
\text { The total international trade between China and Europe }\end{array}$ \\
\hline \multirow{3}{*}{$\begin{array}{l}\text { Freight traffic } \\
\text { safety }\end{array}$} & Safety accidents & $\begin{array}{l}\text { The number of accidents that affected the normal transport of CEFT due to reasons such as } \\
\text { concealing the name of the cargo, overweight, poor loading and reinforcement, and } \\
\text { damaged containers }\end{array}$ \\
\hline & Freight damage and theft & The number of incidents of theft, damage, etc. \\
\hline & Insurance claims business & $\begin{array}{l}\text { The purchase of CEFT full-freight insurance and compensation for the train freight, } \\
\text { including the number of insurance business, the proportion of insurance coverage, and the } \\
\text { number of claims }\end{array}$ \\
\hline
\end{tabular}

experiences, and business executives with at least 10 years of related experiences are selected as the experts to be surveyed.

After 60 experts are selected, we design a questionnaire for assessing the importance of subindicators presented in Table 1. The questionnaire is given in Table 2. Then, we distribute online questionnaires to them through e-mail.
After experts finish them, we collect them automatically, and then, based on the quantitative statistical results of the questionnaire and the availability of data, we obtain the final CEFT's efficiency evaluation indicator system, which includes 8 key subindicators. The specific results are shown in Table 3. 
TABLE 2: Questionnaire of the importance ratings of subindicators of evaluating CEFT's operation efficiency.

\begin{tabular}{|c|c|c|c|c|c|c|}
\hline Indicator layer & Subindicator layer & $\begin{array}{l}\text { Extremely } \\
\text { important }\end{array}$ & $\begin{array}{c}\text { Very } \\
\text { important }\end{array}$ & Important & $\begin{array}{c}\text { General } \\
\text { important }\end{array}$ & Unimportant \\
\hline Scale range & $\begin{array}{c}\text { Annual operation trains } \\
\text { Annual outbound trains } \\
\text { Annual inbound trains } \\
\text { Annual containers } \\
\text { Annual outbound containers } \\
\text { Annual inbound containers } \\
\text { Train return ratio } \\
\text { Ratio of returned containers } \\
\text { Domestic cities } \\
\text { Overseas cities } \\
\text { Container conversion }\end{array}$ & & & & & \\
\hline Speed efficiency & $\begin{array}{c}\text { Average time } \\
\text { Average speed }\end{array}$ & & & & & \\
\hline Transport efficiency & $\begin{array}{c}\text { Operating lines } \\
\text { Entry-exit nodes } \\
\text { Capacity utilization } \\
\text { Average static load rate } \\
\text { Full-capacity rate } \\
\text { Fulfilled rate } \\
\text { Loaded container rate } \\
\end{array}$ & & & & & \\
\hline Operation cost & $\begin{array}{c}\text { Average freight charges of } \\
\text { operation } \\
\text { Government subsidy }\end{array}$ & & & & & \\
\hline $\begin{array}{l}\text { Economic and trade } \\
\text { contribution }\end{array}$ & $\begin{array}{c}\text { Total value of annual freight } \\
\text { Total value of the outbound } \\
\text { freight } \\
\text { Total value of the inbound } \\
\text { freight } \\
\text { Unit TEU value } \\
\text { Outbound unit TEU value } \\
\text { Inbound unit TEU value } \\
\text { Ratio of key categories } \\
\text { China-EU total trade }\end{array}$ & & & & & \\
\hline Freight traffic safety & $\begin{array}{l}\text { Safety accidents } \\
\text { Freight damage and theft } \\
\text { Insurance claims business }\end{array}$ & & & & & \\
\hline
\end{tabular}

TABLE 3: Evaluation indicator system of CEFT's overall operation efficiency.

\begin{tabular}{|c|c|c|}
\hline Indicator layer & Subindicator layer & Indicator description \\
\hline \multirow{5}{*}{ Scale range } & $\begin{array}{l}\text { Annual operation } \\
\text { trains }\end{array}$ & The number of annual operation trains \\
\hline & Overseas cities & The number of overseas cities with entry-exit nodes of CEFT \\
\hline & Domestic cities & The number of cities with entry-exit nodes of CEFT in China \\
\hline & Annual containers & The number of all containers actually carried by the CEFT in one year \\
\hline & Train return ratio & $\begin{array}{l}\text { The ratio of the returned trips to the total trips, reflecting the balance of the two-way } \\
\text { trips between China and Europe }\end{array}$ \\
\hline \multirow[t]{2}{*}{ Transport efficiency } & Operating lines & $\begin{array}{l}\text { The number of CEFT running lines among China, Europe, and countries along the belt } \\
\text { and road, including trunk lines and branch lines }\end{array}$ \\
\hline & Entry-exit nodes & The number of entry-exit nodes of CEFT in China \\
\hline $\begin{array}{l}\text { Economic and trade } \\
\text { contribution }\end{array}$ & $\begin{array}{l}\text { Total value of annual } \\
\text { freight }\end{array}$ & $\begin{array}{l}\text { The value of importing and exporting freights on CEFT, reflecting the status and role of } \\
\text { CEFT in China-EU economic and trade cooperation }\end{array}$ \\
\hline
\end{tabular}

In order to meet the demand for the evaluation indicator in the DEA evaluation model, the evaluation indicator system of CEFT's overall operation efficiency was further classified based on the input-output perspective, choosing the annual operation trains (number), overseas cities (number), domestic cities (number), operating lines (number), and entry-exit nodes 
TABLE 4: Input and output indicator system on efficiency evaluation of CEFT's overall operation efficiency.

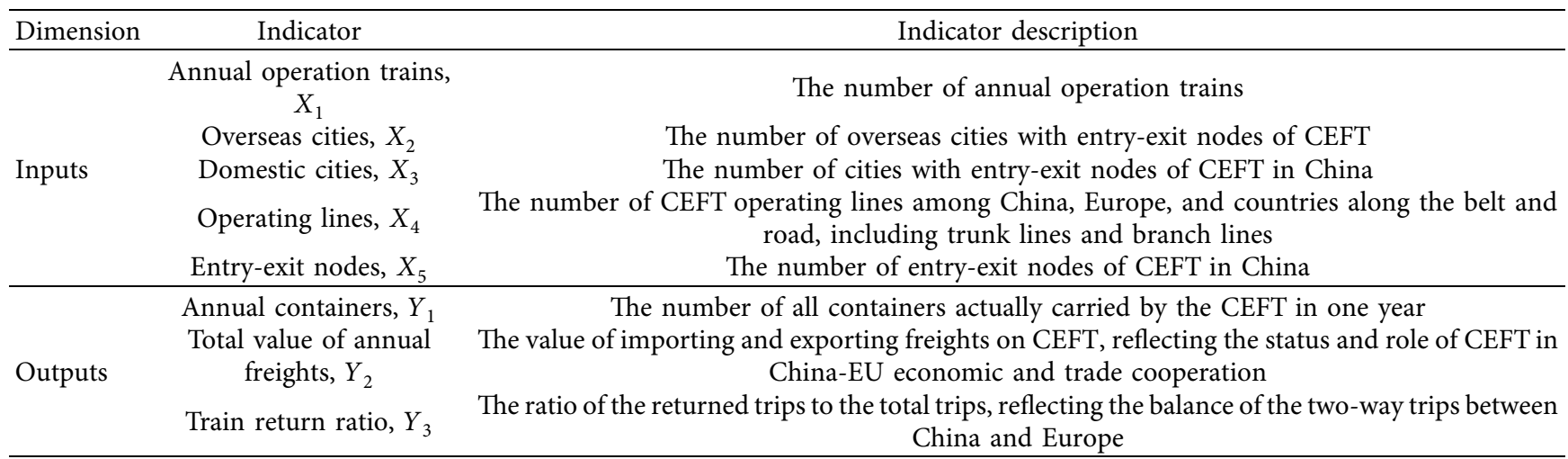

(number) as input index $X_{1}, X_{2}, X_{3}, X_{4}, X_{5}$, respectively and choosing the annual containers (standard container), total value of annual freights (100 million US dollars), and train return ratio (\%) as output index $Y_{1}, Y_{2}, Y_{3}$. The input and output indicator system on efficiency evaluation of CEFT's overall operation efficiency is shown in Table 4.

\section{Design of Evaluation Method for CEFT's Operation Efficiency}

In this paper, we utilized a novel cross-efficiency DEA model embedded with grey correlation analysis to evaluate the operation efficiency of CEFT.

4.1. CCR Model. CCR is the most basic DEA model, which is developed under the assumption that returns to scale is fixed. Suppose there are $n$ decision-making units (DMUs), which are depicted as $\left\{\mathrm{DMU}_{j} \mid j=1,2, \ldots, n\right\}$. For each $\mathrm{DMU}_{j}, m$ input items and $s$ output items are selected, which are represented as $\left\{x_{i j} \mid i=1,2, \ldots m\right\}$ and $\left\{y_{r j} \mid r=1,2, \ldots, s\right\}$, respectively. Besides, let $w_{i}$ be the weight assigned to the $i^{\text {th }}$ input item and $\mu_{r}$ the weight of $r^{\text {th }}$ output item, $i=1,2, \ldots, m$ and $r=1,2, \ldots, s$. Then, the efficiency of $\mathrm{DMU}_{j}$, which can be denoted as $h_{j}$, can be determined by the following equation:

$$
h_{j}=\frac{\sum_{r=1}^{s} \mu_{r} y_{r j}}{\sum_{i=1}^{m} \omega_{i} x_{i j}} .
$$

In the CCR model, the aim is to maximize the efficiency of each DMU denoted as $h_{d}$ under the conditions that the efficiency of any DMU is not greater than 1, and the weights of all inputs and outputs must be greater than 0 . The model can be depicted as follows:

$$
\max \frac{\sum_{r=1}^{s} \mu_{r} y_{\mathrm{rd}}}{\sum_{i=1}^{m} \omega_{i} x_{\mathrm{id}}}=h_{d},
$$

$$
\begin{aligned}
& \text { s.t. }\left\{\frac{\sum_{r=1}^{s} \mu_{r} y_{r j}}{\sum_{i=1}^{m} \omega_{i} x_{i j}} \leq 1, \quad j=1,2, \ldots, n,\right. \\
& \omega_{i} \geq 0, \mu_{r} \geq 0 .
\end{aligned}
$$

The above model can be further transformed to a linear programming model, which is presented as follows:

$$
\begin{aligned}
& \max \sum_{r=1}^{s} \mu_{r} y_{\mathrm{rd}}=h_{d} \\
& \text { s.t. }\left\{\begin{array}{l}
\frac{\sum_{r=1}^{s} \mu_{r} y_{r j}}{\sum_{i=1}^{m} \omega_{i} x_{i j}} \leq 1, j=1,2, \ldots, n \\
\sum_{i=1}^{m} \omega_{i} x_{i d}=1 \\
\omega_{i} \geq 0, \mu_{r} \geq 0, \quad i=1,2, \ldots, m, r=1,2, \ldots, s .
\end{array}\right.
\end{aligned}
$$

The CCR model seeks a set of values for input and output weights to maximize $h_{d}$. Solving the CCR model, if $h_{d}=1$, then $\mathrm{DMU}_{d}$ is weakly efficient; if $h_{d}=1$ and $\omega_{i} \geq 0$, $\mu_{j} \geq 0$, then $\mathrm{DMU}_{d}$ is efficient; if $h_{d}<1$, then $\mathrm{DMU}_{d}$ is inefficient.

4.2. Cross-Efficiency DEA. Cross-efficiency DEA, proposed by Sexton et al., is an extension to the traditional DEA model. Compared with the CCR model, the cross-efficiency DEA model is developed based on the combination of peerappraisal and self-appraisal and can provide a ranking among the DMUs.

Let $\mathrm{DMU}_{j_{0}}$ be the target DMU. Using model (3), we can obtain the optimal values including the weights of input items and output items, which are represented as $\left\{\mu_{r j_{0}}^{*} \mid x=1,2, \ldots, s\right\} \quad$ and $\quad\left\{\omega_{i j_{0}}^{*} \mid i=1,2, \ldots, m\right\}$, 
respectively. Then, the cross-efficiency of $\mathrm{DMU}_{j}$ can be determined by the following equation

$$
E_{j_{0} j}=\frac{\sum_{r=1}^{s} \mu_{r j_{0}}^{*} y_{r j}}{\sum_{i=1}^{m} \omega_{i j_{0}}^{*} x_{i j}}
$$

in which $j_{0}, j=1,2, \ldots, n$. Using the above equation, we can construct a cross-efficiency matrix, which is depicted in Table 5.

Then, we can calculate the value of average crossefficiency of $\mathrm{DMU}_{j}$ :

$$
E_{j}=\frac{1}{n} \sum_{j_{0}}^{n} E j_{0} j, \quad j=1,2, \ldots, n .
$$

Then, we can rank all the DMUs based on the values of their cross-efficiency $E_{j}(j=1,2, \ldots, n)$. Besides, we can further compare the efficiency $E_{j j}$ obtained by self-appraisal with 1 to determine whether or not $\mathrm{DMU}_{j}$ is efficient. If $E_{j j}=1$, then $\mathrm{DMU}_{j}$ is efficient; Else, $\mathrm{DMU}_{j}$ is inefficient.

\subsection{Cross-Efficiency DEA Embedded with Grey Correlation} Analysis. This paper incorporated grey correlation analysis into the traditional cross-efficiency DEA model to enable the novel model to be solved under the condition that the weights of inputs or outputs had fixed relative values.

Firstly, the weights of input and output items are determined by grey correlation analysis. Taking determining the weights of input items as an example, we let the reference values denoted as $X_{0}=\left\{X_{0}(1), X_{0}(2), \ldots, X_{0}(m)\right\}$ and let the input values of the target $\mathrm{DMU}, \mathrm{DMU}_{j}$, as $\left\{x_{i j} \mid i=1,2, \ldots, m\right\}$, $j=1,2 \ldots, n$. Then, the correlation coefficient between input values of $\mathrm{DMU}_{j}$ and reference values can be determined as follows:

$$
r_{i j}=\frac{\Delta \min +\zeta \Delta \max }{\left|X_{0}(i)-x_{i j}\right|+\zeta \Delta \max },
$$

where $\zeta \in[0,1]$ is the resolution coefficient and $\zeta$ typically takes the value of 0.5 . In addition, $\Delta \min =\min _{j} \min _{i} \mid X_{0}(i)-$ $x_{i j} \mid$ and $\Delta \max =\max \max \left|X_{0}(i)-x_{i j}\right|$.

Then, for target $\operatorname{DMU}^{j} \operatorname{DMU}_{j}(j=1,2, \ldots, n)$, we can obtain the correlation weights of inputs $\left\{\tau_{1 j}, \tau_{2 j}, \ldots, \tau_{m j}\right\}$, in which $\tau_{i}$ is determined as follows:

$$
\tau_{i j}=\frac{r_{i j}}{\sum_{i=1}^{m} r_{i j}}, \quad i=1,2, \ldots, m .
$$

Similarly, we can calculate the correlation weights of outputs, which are denoted as $\left\{\pi_{1 j}, \pi_{2 j}, \ldots, \pi_{s j}\right\}$.

Then, we extract the relative size relationship from the obtained weights as the conditions and develop a novel crossefficiency DEA model, which can be depicted as follows:
TABLE 5: Cross-efficiency matrix for DMUs.

\begin{tabular}{lcccc}
\hline \multirow{2}{*}{ Target DMU } & \multicolumn{4}{c}{ DMU } \\
& 1 & 2 & $\ldots$ & $n$ \\
\hline 1 & $E_{11}$ & $E_{12}$ & $\ldots$ & $E_{1 n}$ \\
2 & $E_{21}$ & $E_{22}$ & $\ldots$ & $E_{2 n}$ \\
3 & $E_{31}$ & $E_{32}$ & $\ldots$ & $E_{3 n}$ \\
$\ldots$ & $\ldots$ & $\ldots$ & $\ldots$ & $\ldots$ \\
$n$ & $E_{n 1}$ & $E_{n 2}$ & $\ldots$ & $E_{n n}$ \\
\hline Average cross-efficiency & $E_{1}$ & $E_{2}$ & $\ldots$ & $E_{n}$ \\
\hline
\end{tabular}

$$
\begin{aligned}
& \max \sum_{r=1}^{s} \mu_{r} y_{\mathrm{rd}}=h_{d} \\
& \text { s.t. }\left\{\begin{array}{l}
\frac{\sum_{r=1}^{s} \mu_{r} y_{r j}}{\sum_{i=1}^{m} \omega_{i} x_{i j}} \leq 1, \quad j=1,2, \ldots, n \\
\sum_{i=1}^{m} \omega_{i} x_{i d}=1 \\
\omega_{i}=\gamma \tau_{i d}, \quad i=1,2, \ldots, m \\
\mu_{r}=\sigma \pi_{\mathrm{rd}}, \quad r=1,2, \ldots, s \\
\gamma \geq 0, \sigma \geq 0,
\end{array}\right.
\end{aligned}
$$

where $\gamma$ and $\sigma$ are the independent variables and $\omega_{i}$ and $\mu_{r}$ are the interdependent variables. Solving model (8), we can obtain the efficient values of $\mathrm{DMU}_{d}$, $d=1,2, \ldots, n$.

\section{Empirical Research}

5.1. Data Sources. The paper collected the data from the official website of China-Europe Freight Train and other official sources. The data of input and output indicators are presented in Table 6.

5.2. Data Analysis. Firstly, we should normalize the collected data. We could classify indicators into two classes, i.e., cost indicators and benefit indicators.

Taking the values of input indicators as an example, for cost indicators, the normalized value $\bar{x}_{i j}$ could be determined by the following formula:

$$
\bar{x}_{i j}=\frac{\max _{j} x_{i j}-x_{i j}}{\max _{j} x_{i j}-\min _{j} x_{i j}} .
$$

For benefit indicators, the normalized value $\bar{x}_{i j}$ was determined as follows:

$$
\bar{x}_{i j}=\frac{x_{i j}-\min _{j} x_{i j}}{\max _{j} x_{i j}-\min _{j} x_{i j}} .
$$

Following the above two equations, we could obtain the normalized data, which is presented in Table 7.

Then, we calculate the reference values $(0.2000,0.2000$, $0.4000,0.4000,0.4643,0.8000,0.8769$, and 1.0000$)$ by 
Table 6: Annual data of input and output indicators.

\begin{tabular}{|c|c|c|c|c|c|c|c|c|}
\hline \multirow[b]{2}{*}{ Year } & \multicolumn{5}{|c|}{ Input } & \multicolumn{3}{|c|}{ Output } \\
\hline & $\begin{array}{c}\text { Annual operation } \\
\text { trains }\end{array}$ & $\begin{array}{c}\text { Overseas } \\
\text { cities }\end{array}$ & $\begin{array}{l}\text { Domestic } \\
\text { cities }\end{array}$ & $\begin{array}{c}\text { Operating } \\
\text { lines }\end{array}$ & $\begin{array}{c}\text { Entry-exit } \\
\text { nodes }\end{array}$ & $\begin{array}{c}\text { Annual } \\
\text { containers }\end{array}$ & $\begin{array}{l}\text { Total value of } \\
\text { annual freights }\end{array}$ & $\begin{array}{l}\text { Train return } \\
\text { ratio }\end{array}$ \\
\hline 2011 & 17 & 1 & 1 & 1 & 1 & 1404 & 0.7 & 0 \\
\hline 2012 & 42 & 2 & 3 & 3 & 1 & 3674 & 1.84 & 0 \\
\hline 2013 & 80 & 8 & 6 & 8 & 2 & 6960 & 4.61 & 0 \\
\hline 2014 & 308 & 9 & 7 & 10 & 2 & 26078 & 13.04 & 9.1 \\
\hline 2015 & 815 & 11 & 10 & 21 & 2 & 68902 & 34.45 & 32.5 \\
\hline 2016 & 1702 & 13 & 15 & 26 & 4 & 145794 & 72.9 & 33.6 \\
\hline 2017 & 3673 & 34 & 35 & 57 & 4 & 317930 & 145 & 34.7 \\
\hline 2018 & 6363 & 49 & 56 & 65 & 5 & 533268 & 248.11 & 42.3 \\
\hline
\end{tabular}

maximizing the data in each row of the input part of Table 7 to determine the weights of input criteria. Following the calculation process described in the above section, we could determine the correlation coefficients and correlation weights, which are presented in Table 8 and Figure 1.

In order to validate the advantages of the proposed model, we used the traditional DEA model and cross-efficiency DEA to calculate the efficiencies of CEFT, respectively. The results obtained by the three models are presented in Table 9 and Figure 2.

5.3. Analysis of the Effectiveness of Evaluation Methods. It could be seen from Table 9 and Figure 2 that for the traditional DEA model, it was difficult to completely distinguish all decision-making units and could not guarantee the uniqueness of the evaluation results. The efficiency value of the cross-efficiency DEA model has exceeded 0.7 in 2014, which was slightly inconsistent with the actual operating situation, and due to the limitation of the number of operating years of CEFT in the research object of this paper, there were fewer decision-making units and the crossefficiency DEA model has completely distinguished the decision-making units. However, with the increase in the number of operation trains, the crossefficiency model was not suitable for the evaluation of the operating efficiency of CEFT. Compared with the traditional DEA model and the cross-efficiency DEA model, the efficiency of the crossefficiency evaluation method with the grey relation constraints was closer to the actual operating situation after considering the correlation of each indicator, and it was also easy to completely distinguish the decision-making units. Besides, the discriminating ability has been enhanced, and the evaluation results tended to be stable. Therefore, the results of the grey cross-efficiency DEA were used as examples for analysis. An efficiency value greater than 0.6 and less than 1 was called effective and if it was less than 0.6 , it was called ineffective. Based on the results in Table 9, the CEFT from 2011 to 2018 can be divided into two echelons; the first echelon which included the years of 2011 and 2012 was ineffective; the second echelon which included the years of 2013, 2014, 2015, 2016, 2017, and 2018 was effective.
5.4. Analysis of Evaluation Results. Based on the evaluation results, the operating efficiency of CEFT in the first two years was ineffective, and the operating efficiency in the next six years was effective, of which the efficiency in 2017-2018 was better. The year of 2013 was a turning point in the operation of CEFT, because the operating efficiency began to be effective, and the efficiency value gradually increased and tended to be stable. Until 2016, the operating efficiency value of CEFT showed a downward trend, while the efficiency value began to rebound in 2017, and the efficiency value reached the highest in 2018.

On the whole, 2011 and 2012 were non-DEA effective evaluation units, and there were obvious problems in both inputs and outputs. 2011 and 2012 were the stages of exploration and development of CEFT where the number of operation trains was less than 50 , the number of domestic cities was 3 , the number of overseas cities was 2 , the number of operating lines was 3 , the number of entry-exit nodes was only one, the number of containers was less than 5,000 TEU, and there was no returned train. Compared with 2011, the growth rate of the number of overseas cities and operating lines reached $200 \%$ in 2012, and the inputs increase in key indicators resulted in a corresponding increase of $162 \%$ and $163 \%$ in the containers and the total value of freights. From the perspective of all input and output indicators, in the invalid decision-making units, insufficient outputs were entirely due to insufficient inputs; so in the next few years, the inputs of various indicators should be increased, especially the number of overseas cities and operating lines.

From 2013 to 2016, the period was a low-efficiency decision-making unit, and there were unreasonable structural problems in inputs and outputs. These four years served as the rapid development stage of CEFT. In 2014, the containers and the total value of freights far exceeded the sum of the previous three years, with growth rates as high as $275 \%$ and $183 \%$, respectively. In addition, inbound trains began to operate this year and the main benefit was that the two input indicators of the number of operation trains and the number of operating lines were inputted at a growth rate of $285 \%$ and $125 \%$, respectively. However, the other 2 indicators had insufficient input, such as entry-exit nodes and the overseas cities. Therefore, in 2014, the inputs in operation trains and operating lines had a further rise, while the inputs in entry-exit nodes and overseas cities relatively decreased. In 2015, the two indicators 
TABLE 7: Normalized data.

\begin{tabular}{ccccccccc}
\hline Year & $X_{1}$ & $X_{2}$ & $X_{3}$ & $X_{4}$ & $X_{5}$ & $Y_{1}$ & $Y_{2}$ \\
\hline 2011 & 0.0027 & 0.0204 & 0.0179 & 0.0154 & 0.2000 & 0.0026 & 0.0028 & 0.0000 \\
2012 & 0.0066 & 0.0408 & 0.0536 & 0.0462 & 0.2000 & 0.0069 & 0.0074 \\
2013 & 0.0126 & 0.1224 & 0.1250 & 0.1231 & 0.4000 & 0.0131 & 0.0186 & 0.0000 \\
2014 & 0.0484 & 0.2653 & 0.2679 & 0.2769 & 0.4000 & 0.0489 & 0.0526 & 0.2151 \\
2015 & 0.1281 & 0.4490 & 0.4643 & 0.4615 & 0.4000 & 0.1292 & 0.1388 & 0.7683 \\
2016 & 0.2675 & 0.5714 & 0.5536 & 0.6000 & 0.8000 & 0.2734 & 0.2938 & 0.7943 \\
2017 & 0.5772 & 0.6939 & 0.6250 & 0.8769 & 0.8000 & 0.5962 & 0.5844 & 0.8203 \\
2018 & 1.0000 & 1.0000 & 1.0000 & 1.0000 & 1.0000 & 1.0000 & 1.0000 & 1.0000 \\
\hline
\end{tabular}

TABLE 8: Correlation coefficients and correlation weights of indicators.

\begin{tabular}{lcccccccc}
\hline Indicators & $X_{1}$ & $X_{2}$ & $X_{3}$ & $X_{4}$ & $X_{5}$ & $Y_{1}$ & $Y_{2}$ & $Y_{3}$ \\
\hline Correlation coefficients & 0.5297 & 0.6816 & 0.6790 & 0.7449 & 0.9477 & 0.7425 & 0.7456 & 0.9892 \\
Correlation weights & 0.1478 & 0.1902 & 0.1895 & 0.2079 & 0.2645 & 0.2997 & 0.3010 & 0.3993 \\
\hline
\end{tabular}

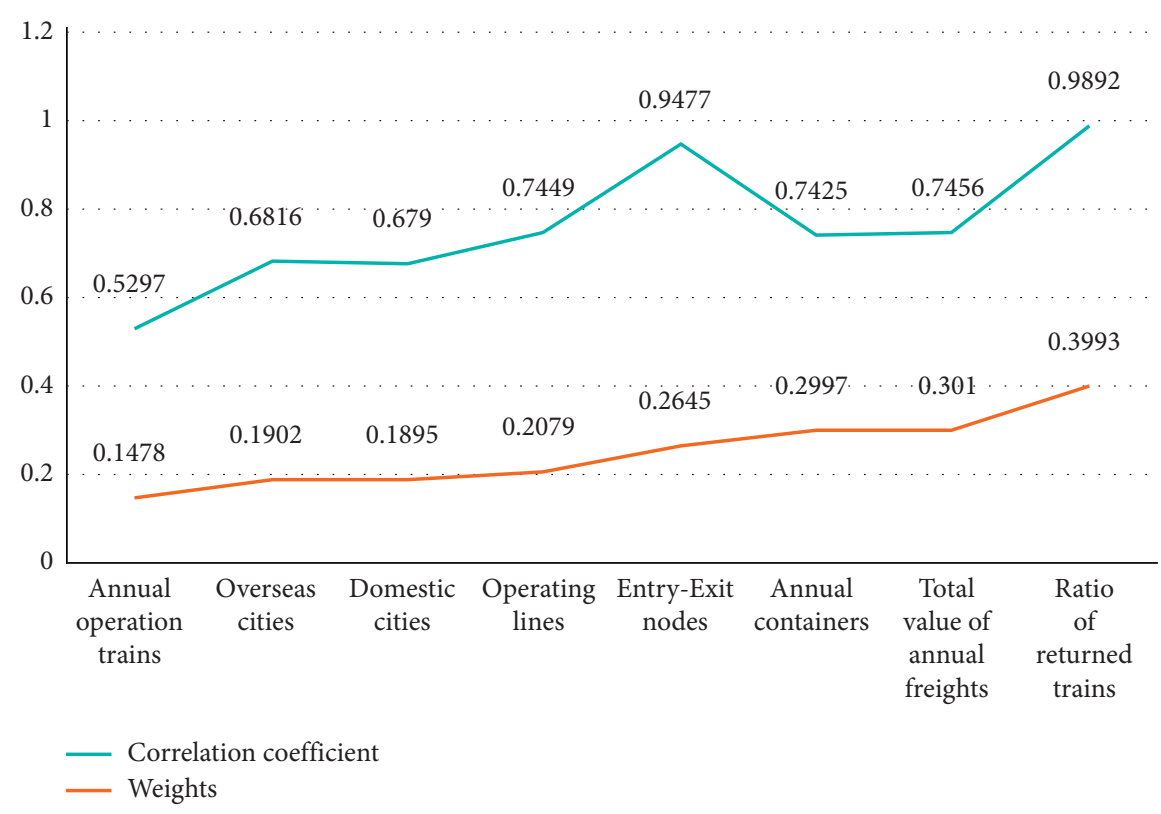

Figure 1: Correlation coefficients and correlation weights of input and output indicators.

TABLE 9: Efficiency values of each DMU.

\begin{tabular}{cccc}
\hline Year & DEA model & $\begin{array}{c}\text { Cross-efficiency } \\
\text { DEA model }\end{array}$ & $\begin{array}{c}\text { The propose } \\
\text { dmodel }\end{array}$ \\
\hline 2011 & 0.9469 & 0.5581 & 0.5401 \\
2012 & 1.0000 & 0.5882 & 0.5692 \\
2013 & 1.0000 & 0.6405 & 0.6295 \\
2014 & 0.9931 & 0.7134 & 0.6934 \\
2015 & 1.0000 & 0.8066 & 0.7906 \\
2016 & 1.0000 & 0.7705 & 0.7595 \\
2017 & 1.0000 & 0.8224 & 0.8094 \\
2018 & 1.0000 & 0.8305 & 0.8145 \\
\hline
\end{tabular}

of operation trains and overseas cities maintained a relatively high growth, making the ratio of returned trains increase $23 \%$, while entry-exit nodes were still insufficient. In 2016, the efficiency value showed a downward trend. Although the growth rate of operation trains was still as high as $109 \%$ and the total number of operation trains exceeded 1500 which was twice the number of operation trains in 2015, the containers and the total value of freights decreased by $52 \%$ year-on-year, and the ratio of returned trains increased only $1 \%$. This showed that at this stage, the operation trains had been inputted too much. Although the containers and the total value of freights have been improved to a certain extent, however, when looking at the ratio of returned trains which reflected the balanced degree of the two-way trains between China and Europe, there were great shortcomings. In terms of inputs in CEFT, simply increasing the number of operation trains would not improve the overall efficiency value. On the contrary, increasing the inputs of unnecessary trains would waste resources and reduce the efficiency value. 


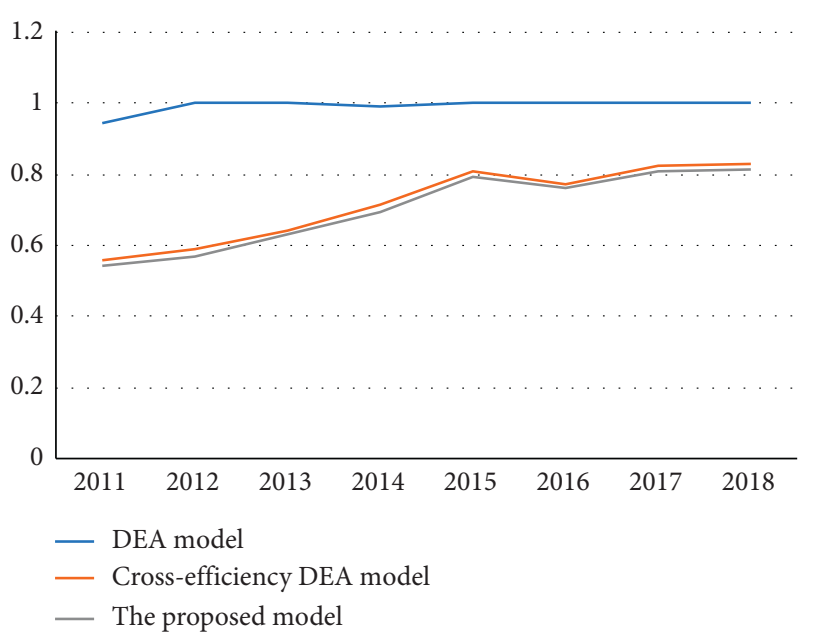

FIgURE 2: Comparison of efficiency values of inputs and outputs of the three models.

The period of 2017 to 2018 was a decision-making unit with better effectiveness, and the CEFT had entered the stage of improving quality and efficiency. In 2017, the operation trains exceeded the total of the previous six years' operation trains and the operating lines increased to 57 with a growth rate of $46 \%$. Correspondingly, the growth rate of the containers also increased by $6 \%$, and the ratio of returned trains also increased. Besides, the increase in the inputs in operating lines has expanded the radiation range of CEFT and enhanced the ability of CEFT to gather supplies. In 2018, the growth of inputs in the number of operation trains, overseas cities, domestic cities, and operating lines dropped sharply, and the growth rates fell by $43 \%, 117 \%, 73 \%$, and $105 \%$, respectively. However, under these circumstances, the total value of freights decreased by only $28 \%$, while the ratio of returned trains increased by $19 \%$, because of the fact that the Suifenhe railway port had already opened the CEFT, and the increase in entry-exit nodes had improved the efficiency of CEFT. The growth rate of the input indicators of various scales in 2018 tended to decrease, indicating that the input and output indicators of CEFT were more rational in structure and this period was in a transition period. The development of CEFT should change from simply pursuing the number of operation trains to improving the quality of trains, and it was not allowed to continue blindly increasing the number of operation trains. On the contrary, the three indicators could be viewed as the focus of future development of CEFT, and they were overseas cities, operating lines, and entry-exit nodes.

\section{Recommendations for Future Efficient and Sustainable Development of China-Europe Freight Train}

Based on the above comprehensive evaluation results of the CEFT's operation efficiency, countermeasures for improving $\mathrm{CEFT}^{\prime}$ operation efficiency in the future will be presented as follows:
(1) To expand CEFT overseas service coverage and increase the number of overseas cities that CEFT connects, CEFT should attach great importance to exploring European market and expanding the coverage of trains in European cities and appropriately increasing the number of overseas cities that CEFT can connect. Specifically, first is that CEFT can work closely with third-party international logistics companies, international freight forwarding companies, and foreign trade manufacturing companies in Europe to give full play to its faster transport than international ocean freight transport and lower cost than international air cargo transport, attracting more suitable sources of international railway transport with better quality and more accurate professional services. The second is to jointly formulate marketing plans and actively carry out logistics business promotion based on different regional characteristics along the CEFT lines and its radiating regions. The third is to steadily promote the layout of cities which CEFT can connect and freight hubs in Europe. In important node cities and cities where freight business is relatively concentrated, CEFT can cultivate and build a number of international railway transport hubs and transit distribution centers, warehouse distribution centers, overseas warehouses, etc., to improve the gathering and transport capacity of the nodes.

(2) To optimize the domestic and international freight hubs of CEFT and moderately supplement the operation lines, CEFT should integrate, expand, and optimize the distribution of freights in both the Chinese market and European market while continuously expanding its service market and service scope in China and Europe. The details are as follows: first, it needs to moderately integrate and merge the distribution and supply of export-oriented freight sources in the Chinese market, rationally divide the service and radiation scope of the CEFT lines in China, and moderately source the freight and form some freight hubs with a certain size in China. The second is to properly integrate and merge the distribution and supply of importoriented freight sources in the European market, to cooperate in depth with various international freight forwarding companies in Europe, and to reasonably divide the service and radiation range of the European and Chinese CEFT lines in the European regions so that it can form some European freight hubs with a certain scale. The third is to integrate and optimize all the existing CEFT lines, which means CEFT should moderately reduce train lines with low transport demand and low transport efficiency, moderately increase CEFT lines with relatively high transport demand and relatively high transportation efficiency, and moderately 
expand or add some new lines to meet with new demands.

(3) To integrate entry-exit node resources of CEFT and to enhance entry-exit nodes' passing capacity, since the establishment of international logistics transport entry-exit nodes is mainly affected by international transport infrastructure, customs, and other fixed facilities, it is difficult to add entry-exit nodes of CEFT on the Chinese border. Therefore, under the current circumstances where the number of entryexit nodes listed by the CEFT is relatively limited, in order to effectively improve the passing capacity of nodes, it can only be turned to integrate the relevant resources of the existing nodes to improve customs clearance efficiency. At the same time, according to statistics, the average detention time of CEFT at border nodes currently accounts for about $30 \%$ of the total time. There are three main reasons. First is the delay in customs clearance due to documents and customs inspections; the second reason is when passing through the nodes, two railway track changes are required, and the efficiency of track change at each node is relatively low. Third, the operational capacity of customs clearance and inspection at border nodes are relatively inadequate, making each node a time lag in customs clearance and inspection. Therefore, on the one hand, it is necessary to coordinate Chinese and foreign railway transport enterprises, customs, and inspection and quarantine departments, systematically sort out, integrate, and simplify the entry-exit customs clearance process of CEFT, eliminate invalid customs clearance links, and improve inefficient customs clearance links and entry-exit customs clearance effectiveness. On the other hand, CEFT can integrate and optimize existing node resources, dig up and make effective use of idle resources, and moderately supplement or add some basic facilities such as customs clearance, inspection, and track changes at various nodes to effectively expand the nodes' customs passing capabilities.

\section{Conclusion}

This paper mainly adopted a new DEA model based on grey cross-efficiency to study the operation efficiency evaluation of CEFT, accurately identified the fundamental problems affecting the operation efficiency of CEFT, and put forward effective future sustainable development countermeasures. The main contributions of this paper were as follows.

Firstly, this paper used the grey correlation weight calculation method to accurately find the relative optimal weight ratio of the input and output indicator of the CEFT operation and then introduced this optimal ratio relationship as a limiting condition to the crossefficiency DEA evaluation model to solve the problem of ignoring the relative size of the input and output indicator weights.
Secondly, the new grey cross-efficiency DEA evaluation model was applied to quantitatively and accurately evaluate the operation efficiency of CEFT. Through accurate evaluation and analysis, it found that the "overseas cities," "operating lines," and "entry-exit nodes" were currently the main influencing factors that restricted the actual operation efficiency of CEFT so that it further indicated the improvement direction for CEFT's future efficient and sustainable development.

However, there still exist some deficiencies waiting to be solved; for example, we do not take the operation efficiency of different trains and further do not account for the interdependent relationship of different trains, which are both our future research directions.

The questionnaire for evaluating the importance ratings of subindicators of assessing CEFT's operation efficiency is presented in Table 2.

\section{Data Availability}

The data used to support the findings of this study are available from the corresponding author upon request.

\section{Conflicts of Interest}

The authors declare that they have no conflicts of interest.

\section{Acknowledgments}

This research has been financed by the National Social Sciences Funding Project (Grant no. 18BGL007); Chongqing Social Sciences Planning Major Project (Grant no. 2018TBWT-ZD07); Chongqing Municipal Education Commission Humanities and Social Sciences Research General Project (Grant no. 18SKGH069); Chongqing Science and Technology Bureau Technology Foresight and Institutional Innovation Project (Grant no. cstc2019jsyjzzysbAX0047); Chongqing Doctoral Program of Social and Scientific Planning (Grant no. 2018BS79); and Scientific Research Start-Up Foundation of Chongqing Technology and Business University (Grant no. 1855016).

\section{References}

[1] Y. Huang and Y. Wang, "How does high-speed railway affect green innovation efficiency? a perspective of innovation factor mobility," Journal of Cleaner Production, vol. 265, 2020.

[2] M. Song, G. Zhang, W. Zeng, J. Liu, and K. Fang, "Railway transportation and environmental efficiency in China," Transportation Research Part D-transport and Environment, vol. 48, pp. 488-498, 2016.

[3] Z. Liu, C.-X. Qin, and Y.-J. Zhang, “The energy-environment efficiency of road and railway sectors in China: evidence from the provincial level," Ecological Indicators, vol. 69, pp. 559570, 2016.

[4] A. Beck, H. Bente, and M. Schilling, "Railway efficiency: an overview and a look at opportunities for improvement," International Transport Forum Discussion Paper, Organisation for Economic Co-operation and Development (OECD), Paris, France, 2013. 
[5] Y. C. Lai, "Increasing railway efficiency and capacity through improved operations," Control and Planning, vol. 69, no. 5, 2008.

[6] M. M. Movahedi, S. Saati, and A. R. Vahidi, "Iranian railway efficiency (1971-2004): an application of DEA," International Journal of Contemporary Mathematical Sciences, vol. 2, no. 32, pp. 1569-1579, 2007.

[7] M. M. Movahedi, S. Y. Abtahi, and M. Motamedi, "Iran railway efficiency analysis, using DEA: an international comparison," International Journal of Applied Operational Research-An Open Access Journal, vol. 1, no. 1, pp. 1-7, 2011.

[8] M.-M. Yu and E. T. J. Lin, "Efficiency and effectiveness in railway performance using a multi-activity network DEA model," Omega, vol. 36, no. 6, pp. 1005-1017, 2008.

[9] M.-M. Yu, "Assessing the technical efficiency, service effectiveness, and technical effectiveness of the world's railways through NDEA analysis," Transportation Research Part A: Policy and Practice, vol. 42, no. 10, pp. 1283-1294, 2008.

[10] L. Li, "Comprehensive efficiency evaluation of Chinese railway systems: based on double-stage and double-activity analysis framework," Nankai Economic Studies, vol. 5, pp. $95-110,2010$

[11] M. K. Sameni and J. Preston, "Value for railway capacity: assessing efficiency of operators in great Britain," Transportation Research Record, vol. 2289, no. 2289, pp. 134-144, 2012.

[12] G. Friebel, M. Ivaldi, and C. Vibes, "Railway (De) Regulation: a European efficiency comparison," Economica, vol. 77, no. 305, pp. 77-91, 2010.

[13] A. Kutlar, A. Kabasakal, and M. Sarikaya, "Determination of the efficiency of the world railway companies by method of DEA and comparison of their efficiency by Tobit analysis," Quality \& Quantity, vol. 47, no. 6, pp. 3575-3602, 2013.

[14] A. Charnes, W. W. Cooper, and E. Rhodes, "Measuring the efficiency of decision making units," European Journal of Operational Research, vol. 2, no. 6, pp. 429-444, 1978.

[15] R. D. Banker, A. Charnes, and W. W. Cooper, "Some models for estimating technical and scale inefficiencies in data envelopment analysis," Management Science, vol. 30, no. 9, pp. 1078-1092, 1984.

[16] T. R. Sexton, R. H. Silkman, and A. J. Hogan, "Data envelopment analysis: critique and extensions," New Directions for Program Evaluation, vol. 1986, no. 32, pp. 73-105, 1986.

[17] R. G. Thompson, F. D. Singleton, R. M. Thrall, and B. A. Smith, "Comparative site evaluations for locating a highenergy physics lab in Texas," Interfaces, vol. 16, no. 6, pp. 35-49, 1986.

[18] A. Charnes, W. W. Cooper, Q. L. Wei, and Z. M. Huang, "Cone ratio data envelopment analysis and multi-objective programming," International Journal of Systems Science, vol. 20, no. 7, pp. 1099-1118, 1989.

[19] L. M. Seiford and J. Zhu, "Infeasibility of super-efficiency data envelopment analysis models," INFOR: Information Systems and Operational Research, vol. 37, no. 2, pp. 174-187, 1999.

[20] R. Mahmoudi, A. Emrouznejad, S.-N. Shetab-Boushehri, and S. R. Hejazi, "The origins, development and future directions of data envelopment analysis approach in transportation systems," Socio-Economic Planning Sciences, vol. 69, p. 100672, 2020.

[21] M. Torres-Samuel, C. L. Vásquez, M. Luna et al., "Performance of education and research in Latin American countries through data envelopment analysis (DEA)," Procedia Computer Science, vol. 170, pp. 1023-1028, 2020.
[22] M. Nahangi, Y. Chen, and B. McCabe, "Safety-based efficiency evaluation of construction sites using data envelopment analysis (DEA)," Safety Science, vol. 113, pp. 382-388, 2019.

[23] S. Chaabouni, "China's regional tourism efficiency: a twostage double bootstrap data envelopment analysis," Journal of Destination Marketing \& Management, vol. 11, pp. 183-191, 2019.

[24] X. Liu, P. Guo, and S. Guo, "Assessing the eco-efficiency of a circular economy system in China's coal mining areas: emergy and data envelopment analysis," Journal of Cleaner Production, vol. 206, pp. 1101-1109, 2019.

[25] S. Kohl, J. Schoenfelder, A. Fügener, and J. O. Brunner, "The use of Data Envelopment Analysis (DEA) in healthcare with a focus on hospitals," Health Care Management Science, vol. 22, no. 2, pp. 245-286, 2019. 